the Festival has become an important rendez-vous for producers and specialists in health education.

\title{
RED CROSS AND THE ENVIRONMENT
}

Pollution is one of the problems most widely discussed today. The Red Cross too is concerned about it. Can National Societies play an effective part in the campaign for a world-wide programme of action? The League review Panorama (1971, No. 3) examines this topical question in a leading article, of which the following is an extract.

... In many people's minds, such progress is praiseworthy but has very little to do with Red Cross. This is to overlook the responsibility of Red Cross as a member of the community-local or international. We can act as a pressure group on the most basic issue of environment: pollution. We are certainly interested in obtaining clean and pleasant surroundings for every family and fresh air and open spaces for young people to grow up in.

Even closer to Red Cross priorities and programmes is the whole area of efforts aimed at improving the quality of life-which could be described as the human environment. In its widest sense this includes improving community relations, reducing tensions and aggressions, promoting friendship between nations, races and social groups within a country. All these are easily recognisable as longstanding aims of Red Cross.

In terms of practical programmes, the fight for a better human environment is reflected over and again in Red Cross social development activities. Our efforts to make life more acceptable in the gigantic suburbs or the slums, to improve housing conditions, to provide space and opportunity for leisure activities, to ensure a normal existence for the old or handicapped, to facilitate human contacts and help people to live happier lives, in the big cities or the backstream of the countryside-all these are activities concerned with the human environment. 


\section{IN THE RED CROSS World}

We must recognise that Red Cross is involved in environment. It is up to us to harness the interest being generated to the benefit of our activities in this field and to realize that we have a meaningful contribution to make here...

\section{France}

We have read in the French Red Cross Review ${ }^{1}$ the following interesting article on "The Red Cross and Present-Day MedicoSocial Problems".

The French Red Cross Society's medico-social vocation is defined in article 1 of the Society's statutes: "The French Red Cross shall work for the prevention and alleviation of all human suffering. It shall participate in all medical preventive efforts, carrying its continuous action beyond disasters, particularly for the benefit of mothers and children ".

This does not mean that the onus of satisfying all needs or even certain needs is on the Society. But it is a service auxiliary to the public authorities and, as such, it must play a part in all efforts in the medico-social field. Its very simple organization enables it to adapt to circumstances. It is for that reason that, for several years in particular, it has unceasingly developed the range of its activities, modernizing and transforming its institutions. This is too little known. The efforts of the French Red Cross to keep abreast of changes in medical technology and to study new fields of action where it might extend its scope must be underlined.

French medical statistics show three main points:

- the decline of tuberculosis;

- longer life of children affected by congenital ailments, infirmities and affections which were formally fatal.

- increase of the elderly population.

These three points have guided the French Red Cross medicosocial policy-making.

1 Vie et Bonté, Paris, May 1971. 